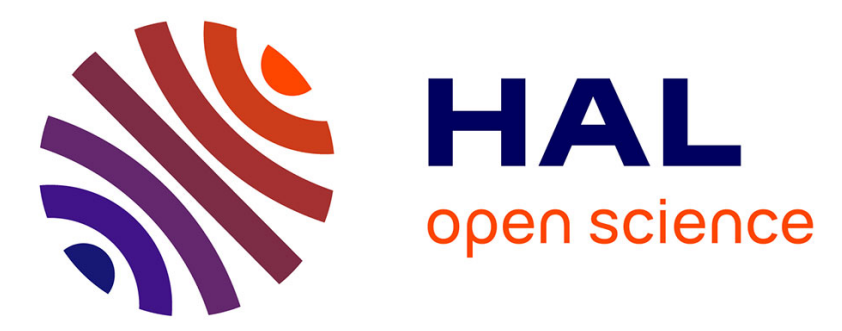

\title{
Excimer laser induced melting and decomposition of technical ceramic surfaces and their properties
}

\author{
J. Grossmann, A. Emmel, E. Schubert, H. Bergmann
}

\section{To cite this version:}

J. Grossmann, A. Emmel, E. Schubert, H. Bergmann. Excimer laser induced melting and decomposition of technical ceramic surfaces and their properties. Journal de Physique IV Proceedings, 1993, 03 (C7), pp.C7-987-C7-990. 10.1051/jp4:19937152 . jpa-00251775

\section{HAL Id: jpa-00251775 https://hal.science/jpa-00251775}

Submitted on 1 Jan 1993

HAL is a multi-disciplinary open access archive for the deposit and dissemination of scientific research documents, whether they are published or not. The documents may come from teaching and research institutions in France or abroad, or from public or private research centers.
L'archive ouverte pluridisciplinaire HAL, est destinée au dépôt et à la diffusion de documents scientifiques de niveau recherche, publiés ou non, émanant des établissements d'enseignement et de recherche français ou étrangers, des laboratoires publics ou privés. 


\title{
Excimer laser induced melting and decomposition of technical ceramic surfaces and their properties
}

\author{
J. GROSSMANN, A. EMMEL ${ }^{*}$, E. SCHUBERT* and H.W. BERGMANN ${ }^{*}$
}

Fraunhofer Institut für Silicatforschung (ISC), Neunerplatz 2, 97082 Würzburg, Germany

* Applikations- und Technikzentrum für Energieverfahrens, Umwelt- und Strömungstechnik

(ATZ-EVUS), Department III, New Materials, New Technologies, Rinostr. 1, 92249 Wilseck, Germany

\begin{abstract}
The chemical, structural and topographical changes after the irradiation of technical oxide $\left(\mathrm{Al}_{2} \mathrm{O}_{3}, \mathrm{ZrO}_{2}\right)$ and nonoxide ceramics $\left(\mathrm{SiC}, \mathrm{Si}_{3} \mathrm{~N}_{4}\right.$ ) with a XeCl-Excimer Laser were studied as function of the applied energy density and number of pulses. The silicon-based nonoxide ceramics decomposed during a temperature and pressure induced process and an adherent up to $1,5 \mu \mathrm{m}$ thick crystalline Si-layer remained on top of the specimen surface. In contrast, the oxide ceramics underwent a melting and rapid resolidification process without a chemical alteration. The minimization of surface defects on $\mathrm{Al}_{2} \mathrm{O}_{3}$ was used to generate a two-fold increase in Weibull's modulus $\mathrm{m}$ compared with untreated samples, whereas the silicon layer on top of $\mathrm{SiC}$ was helpful to generate and improve metal-ceramic joints between SiSiC and AlMgSil.
\end{abstract}

\section{INTRODUCTION AND OBJECTIVES}

The treatment of materials with Excimer Lasers recently lead to some industrial realized applications, like the connection of sheet bares ${ }^{[1]}$, the marking of surface mounted devices (SMD) and glasses ${ }^{[2]}$ and the baring of wires ${ }^{[3]}$. With regard to the treatment of ceramics the recording of ablation rates and microstructuring was reposted. The aim of the present study is to exemplaryly demomstrate the applicability of a one-step surface finishing technique for technical ceramics with an Excimer Laser, maintaining the fundamental dimensions of the workpiece. In addition, the chemical, structural and topographical changes after the irradiation should be determined and interpreted, respectively.

\section{EXPERIMENTALS}

\subsection{Laser treatment}

The surface treatment of the ceramics was carried out with a pulsed XeCl-Excimer Laser ${ }^{(1)}(\lambda=308 \mathrm{~nm}$, pulse length $55 \mathrm{~ns}$, maximum repetition rate $20 \mathrm{~Hz}$ ). The gadget supplied a raw beam with an energy of $2 \mathrm{~J}$, distributed over a rectangular raw beam geometry of $45^{*} 45 \mathrm{~mm}^{2}$. The raw beam was focused onto the flat specimens using two $45^{\circ}$ mirrors and an adjustable focus lense $(f=300 \mathrm{~mm})$. The typical range for the parameters was $10-80 \mathrm{~mJ} / \mathrm{mm}^{2}$ for the energy density and $1-32$ pulses per area. The variation in energy density was estimated to be smaller than $10 \%$. The irradiation of the samples was obtained by a meander-like scanning ("flying" mode) of the flat specimens.

(1) Siemens XP 2020 


\subsection{Materials}

The materials used in this study were commercial nonoxide ceramics, especially $\mathrm{SiC}$ and $\mathrm{Si}_{3} \mathrm{~N}_{4}$ (SSiC, pressureless sintered $\mathrm{SiC}$, SiSiC, silicon infiltrated SiC, HIPRBSN, hot isostatic pressed reaction bonded $\left.\mathrm{Si}_{3} \mathrm{~N}_{4}\right)$ and oxide ceramics, like $\mathrm{Al}_{2} \mathrm{O}_{3}$ and $\mathrm{ZrO}_{2}\left(\mathrm{Al}_{2} \mathrm{O}_{3}, 96 \%, 98 \%\right.$ and $99,7 \%$ purity, $\mathrm{Y}-\mathrm{PSZ}, \mathrm{Yttria}$ partially stabilized zirconia, sintered and plasma sprayed), respectively. The combination of SiSiC and the aluminum alloy AlMgSil (3.2315) was selected for the diffusion welding of metal-ceramic joints.

\subsection{Diffusion welding}

The diffusion welding of AlMgSil versus SiSiC was carried out at $530^{\circ} \mathrm{C} / \mathrm{lh} / \mathrm{Air}$ with an applied pressure of $25-31 \mathrm{~N} / \mathrm{mm}^{2}$. A sandwich construction of an aluminum sheet $\left(40 * 40 \mathrm{~mm}^{2}\right.$, thickness 2 $\mathrm{mm}$ ) between two $\mathrm{SiC}$ rings (outer diameter $35 \mathrm{~mm}$, inner diameter $21 \mathrm{~mm}$, thickness $7 \mathrm{~mm}$ ) was used. Before joining the Al-sheet were cleaned in $10 \% \mathrm{HF}$, whereby the SiSiC underwent a Laser pretreatment.

\subsection{Characterization}

The topographical changes of the sample were monitored by roughness measurements according to DIN 4768 and DIN 4772 and expanded by Scanning Electron Microscopy (SEM) observation. The thickness of the modified surface layers was detected on fractured surfaces by the SEM technique. X-Ray Diffraction (XRD) and Auger Electron Spectroscopy (AES) revealed the chemical and structural changes after irradiation. The mechanical properties (hardness, Young's modulus) of the altered surfaces were monitored by microhardness tests (Load: $0,4-256 \mathrm{mN}$ ) using a Berkovich diamond indenter. The interaction of the components during diffusion welding was determined by Energy Dispersive X-Ray Spectroscopy (EDX) on polished cross sections. The shear strength $\tau$ of the joints was determined in comparison with glued samples (commercial two component epoxy glue) of the same geometry. Finally, the strength $\sigma_{4 \mathrm{~PB}}$ of irradiated samples was determined by 4-point bending according to DIN 51110 .

\section{Results AND Discussion}

\subsection{Nonoxide Ceramics}

As demonstrated for $\mathrm{SSiC}$ in Fig. 1, the surface roughness can be tailored in dependence of the applied energy density and the number of pulses. In general a roughening after the first pulse took place due to the cleaning of the suface. Medium numbers of pulses ( $4-8$ pulses) lead to a minimized surface roughness. The surface consisted of a coherent resolidified layer. Surface defects like pores, which are visible in the untreated sample have been reduced. A further increase of the applied number of pulses generated a regular "hilly" structure, which is associated with an increase in roughness.

The irradiation of the silicon-based ceramics generated an up to $1-1,5 \mu \mathrm{m}$ thick modified layer, Fig. 2 shows an example for SiSiC. XRD measurement, performed on $\mathrm{SSiC}$, revealed the existance of crystalline $\mathrm{Si}$-peaks.

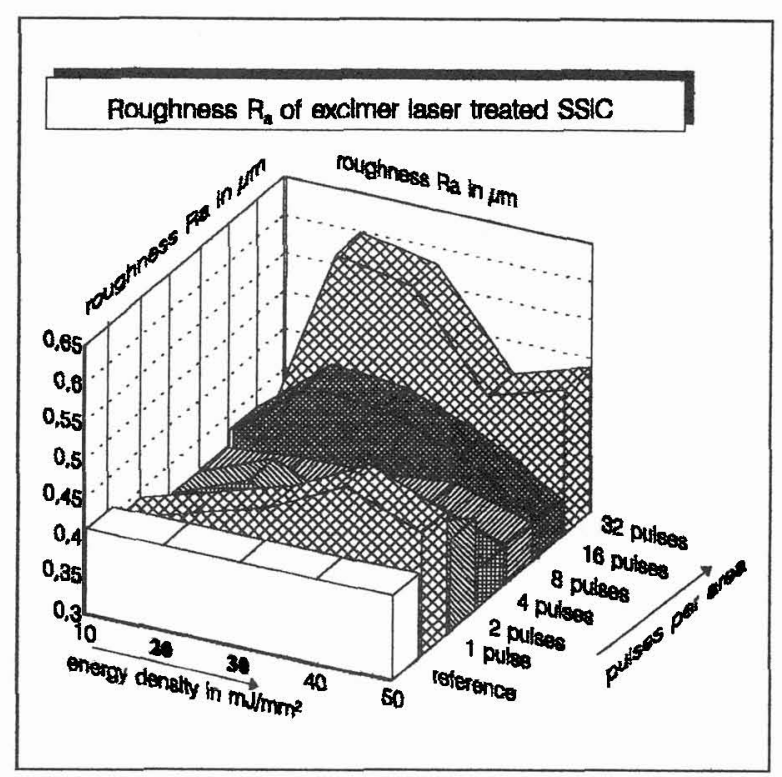

Fig. 1: Roughness measurements of untreated and excimer laser treated SSiC 
The comparatively large half-width of those peaks indicated a small crystallite size, caused by rapid solidification of the melted surface. Due to this silicon layer, the electrical conductivity increased by the factor $10^{2}$.

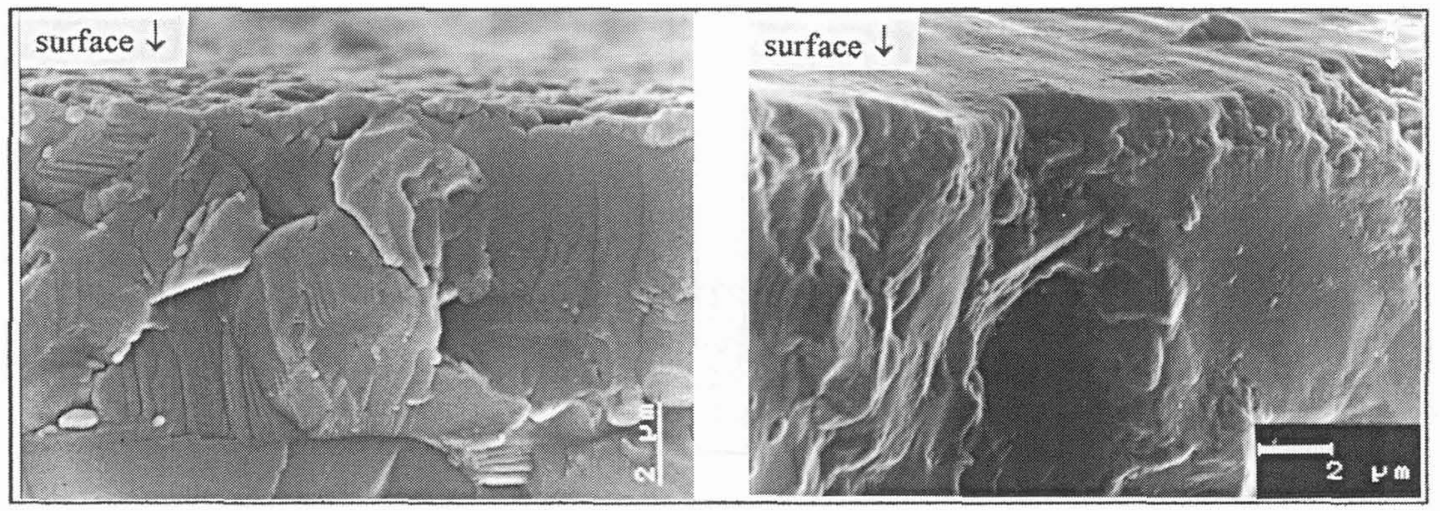

Fig. 2: SEM-pictures of untreated (left hand side) and excimer laser treated $\left(30 \mathrm{~mJ} / \mathrm{mm}^{2}, 8\right.$ pulses) cracked SiSiC-specimen

During the irradiation a temperature and pressure induced decomposition of $\mathrm{SiC}$ and $\mathrm{Si}_{3} \mathrm{~N}_{4}$ took place, respectively. The pressure in the order of some kbar during the plasma development thermodynamically favoured the existance of a Si-rich melt, whereby $C$ and $N$ evaporated into the environment, respectively. AES measurements on SiSiC indicated a homogeneous distribution of $\mathrm{Si}$ and $\mathrm{C}$ up to a depth of about $1,5 \mu \mathrm{m}$, whereby the Si-concentration increased approximately from $50 \mathrm{~mole}-\%$ to 75 mole- $\%$ and as a countermove the C-concentration was reduced from 50 mole- $\%$ to 25 mole- $\%$. For $\mathrm{SSiC}$ the Si-concentration was somewhat lower.

Application:

The Laser pretreatment of SiSiC enabled the formation of joints by diffusion welding with AlMgSil. Without the pretreatment of $\mathrm{SiC}$ no joining took place. The joints withstood up to approximately $\tau=$ $58 \mathrm{~N} / \mathrm{mm}^{2}$, whereas the glued samples only reached about $25-30 \mathrm{~N} / \mathrm{mm}^{2}$. The specimens always fractured in the ceramic piece and typically shear lips with a $45^{\circ}$ angle were observed. The EDX profile exhibited an interdiffusion zone of Si and $\mathrm{Al}$ of about $7 \mu \mathrm{m}$ thickness.

\subsection{Oxide Ceramics}

Similar to the nonoxide ceramics the roughness of the oxide ceramics can be changed by the Laser treatment. For $\mathrm{Al}_{2} \mathrm{O}_{3}$ medium energy densities $\left(20-30 \mathrm{~mJ} / \mathrm{mm}^{2}\right)$ minimized the roughness, whereas large numbers of applied pulses (16-32) and higher energy densities $\left(40 \mathrm{~mJ} / \mathrm{mm}^{2}\right)$ roughend the surface.

A drastic surface smoothing can be achieved especially in the case of the plasma sprayed $\mathrm{ZrO}_{2}$. Reasons are the evaporation of tops and the fact that the lifetime of the melt exceeded the pulse duration (caused by the low thermal conductivity of zirconia), so that the melt flattens out on the top.

In contrast to the nonoxide ceramics no decomposition of the oxide melts took place and the surface layer underwent a melting and resolidification process. The surface of zirconia consisted of an up to 2 $\mu \mathrm{m}$ thick layer and an epitaxial resolidification took place. Cracks were always present and divided the surface into equally sized segments. These cracks were generated by tensile stresses during cooling. The surface of $\mathrm{Al}_{2} \mathrm{O}_{3}$ consisted of an 0,5 - $1 \mu \mathrm{m}$ thick layer. An elimination of surface defects and pores was observed in those remelted layers.

The microhardness measurement (Fig. $3 \mathrm{a}$ and b) performed on $\mathrm{Al}_{2} \mathrm{O}_{3}$ revealed three effects: (i) under the same load the indenter penetrates deeper into the Laser treated material (ii) with increasing indenter 
displacement the load displacement curves and the slopes approached each other, respectively (iii) the hardness versus displacement curves and the SEM observations were in good agreement with hardness measurements of amorphous $\mathrm{Al}_{2} \mathrm{O}_{3}{ }^{[4]}$, which supported the assumption that the Excimer Laser treatment generated an amorphous $\mathrm{Al}_{2} \mathrm{O}_{3}$ top layer. Consequently, Young's Modulus was reduced to approximately $200 \mathrm{GPa}$ compared with $400 \mathrm{GPa}$ for the untreated material.

The reduction and elimination of surface defects on the alumina surfaces resulted in an increase in reliability. As an example, Weibull's Moduls m underwent a two-fold increase from $m=7,8$ for the untreated material to $\mathrm{m}=16$ for the irradiated $\mathrm{Al}_{2} \mathrm{O}_{3}$ (30 $\mathrm{mJ} / \mathrm{mm}^{2}, 16$ pulses) of $96 \%$ purity. With respect to the standard deviation, these effects are independent of the alumina purity ${ }^{[5]}$.

\section{LTERATURe}

[1] F. Bachmann and P. Holzer, Laser Praxis, Carl Hanser Verlag, München, L31 - 35 (1986).

[2] U. Sowada et al., World Laser Almanac 1, 50 - 51 (1988).

[3] P. Holzer and F. Bachmann, Kunststoffe 79 (6), 485 - 490 (1989).

[4] W.C. Oliver et al., Thin Solid Films, $153,185-196$ (1987).

[5] E. Schubert and H.W. Bergmann, Surface Engineering, 9, 77 - 81 (1993)

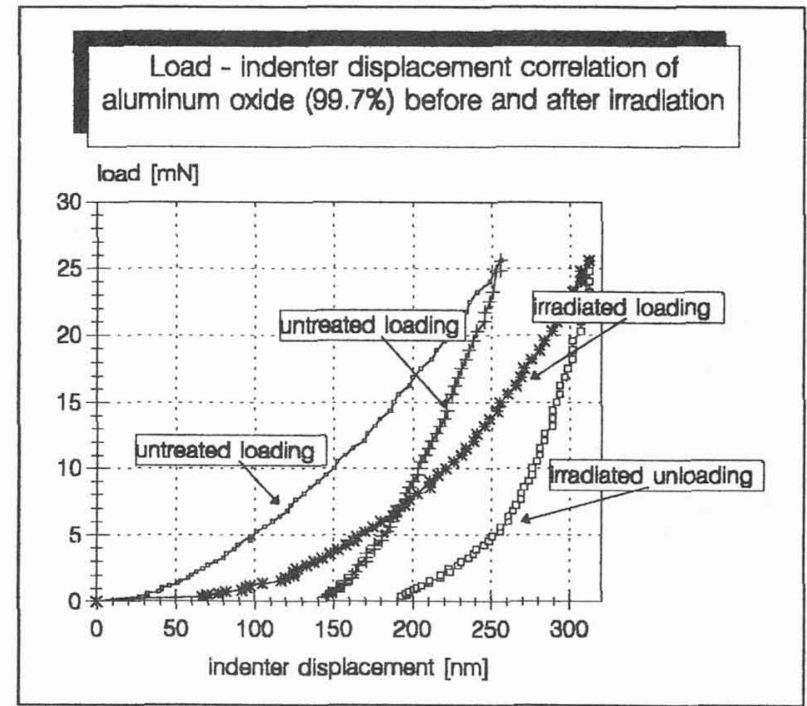

Fig. 3 a: Load-indenter displacement of untreated and excimer laser treated $\left(30 \mathrm{~mJ} / \mathrm{mm}^{2}, 16\right.$ pulses $) \mathrm{Al}_{2} \mathrm{O}_{3}$

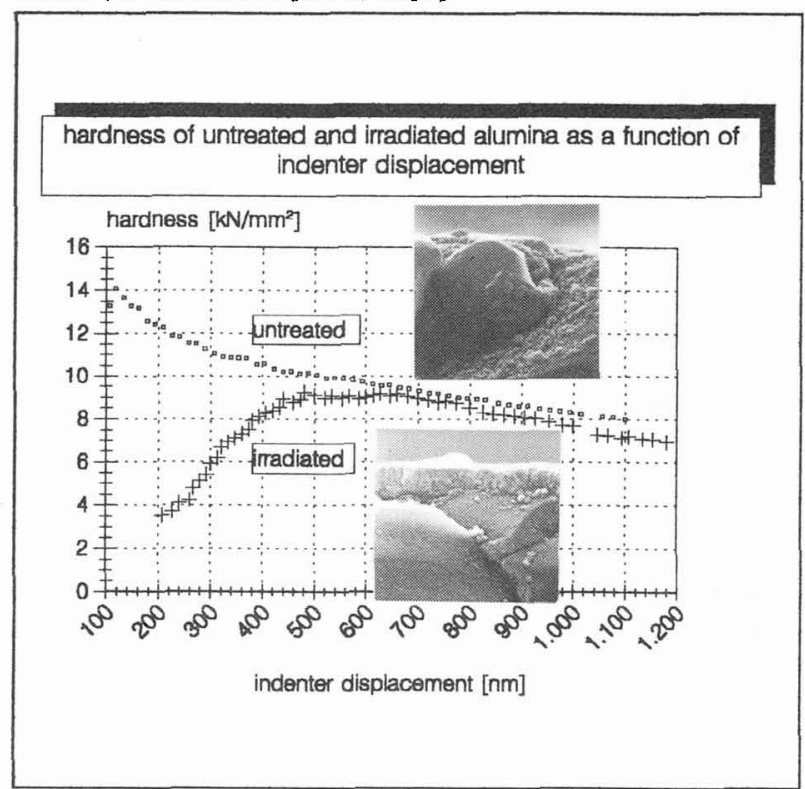

Fig. $3 \mathrm{~b}:$ Hardness of untreated and excimer treated $\left(30 \mathrm{~mJ} / \mathrm{mm}^{2}, 16\right.$ pulses) $\mathrm{Al}_{2} \mathrm{O}_{3}$ 